\title{
Erratum to: Assessing the potential impact on the thyroid axis of environmentally relevant food constituents/contaminants in humans
}

\author{
Gerhard Eisenbrand $^{1} \cdot$ Heinz-Peter Gelbke ${ }^{2}$
}

Published online: 30 June 2016

(C) Springer-Verlag Berlin Heidelberg 2016

\section{Erratum to: Arch Toxicol \\ DOI 10.1007/s00204-016-1735-6}

Unfortunately, two references in the original article have been cited in the wrong context.

In the section "Risk assessment under consideration of background exposures to NIS inhibitors", the reference to Braverman et al. (2005) should be replaced by Greer et al. (2002) and the reference to Wolff and Murray (1963) should be replaced by the new reference Weterings et al. (2016).

Weterings PJJM, Loftus C, Lewandowski TA (2016) Derivation of the critical effect size/benchmark response for the dose-response analysis of the uptake of radioactive iodine in the human thyroid. Toxicol Lett. doi:10.1016/j. toxlet.2016.06.004.

The missing funding information is given below the Acknowledgment section.

Acknowledgments This work was funded by the fertilizer industry.

The online version of the original article can be found under doi:10.1007/s00204-016-1735-6.

Gerhard Eisenbrand

eisenbra@rhrk.uni-kl.de

Kuehler Grund 48/1, 60126 Heidelberg, Germany

2 CinTox, 381, Avenue de Pessicart, 06100 Nice, France 